\title{
The Acidic Tumor Microenvironment Promotes the Reconversion of Nitrite into Nitric Oxide: Towards a New and Safe Radiosensitizing Strategy
}

\author{
Françoise Frérart, ${ }^{1}$ Pierre Sonveaux, ${ }^{1}$ Géraldine Rath, ${ }^{1}$ Alexandra Smoos, ${ }^{1}$ Ahlam Meqor, \\ Nicolas Charlier, ${ }^{2}$ Bénédicte F. Jordan, ${ }^{2}$ Julie Saliez, ${ }^{1}$ Agnès Noël, ${ }^{3}$ Chantal Dessy, \\ Bernard Gallez, ${ }^{2}$ and Olivier Feron ${ }^{1}$
}

\begin{abstract}
Purpose: The biological status of nitrite recently evolved from an inactive end product of nitric oxide catabolism to the largest intravascular and tissue storage of nitric oxide (NO). Although low partial $\mathrm{O}_{2}$ pressure favors enzymatic reconversion of nitrite into $\mathrm{NO}$, low $\mathrm{pH}$ supports a nonenzymatic pathway. Because hypoxia and acidity are characteristics of the tumor microenvironment, we examined whether nitrite injection could preferentially lead to NO production in tumors and influence response to treatments.

Experimental Design: The effects of nitrite were evaluated on arteriole vasorelaxation, tumor cell respiration and tumor blood flow, oxygenation, and response to radiotherapy.

Results: We first showed that a small drop in $\mathrm{pH}(-0.6 \mathrm{pH}$ unit) favored the production of bioactive NO from nitrite by documenting a higher cyclic guanosine $3^{\prime}, 5^{\prime}$-monophosphate dependent arteriole vasorelaxation. We then documented that an i.v. bolus injection of nitrite to tumor-bearing mice led to a transient increase in partial $\mathrm{O}_{2}$ pressure in tumor but not in healthy tissues. Blood flow measurements failed to reveal an effect of nitrite on tumor perfusion, but we found that $\mathrm{O}_{2}$ consumption by nitrite-exposed tumor cells was decreased at acidic $\mathrm{pH}$. Finally, we showed that low dose of nitrite could sensitize tumors to radiotherapy, leading to a significant growth delay and an increase in mouse survival (versus irradiation alone).

Conclusions: This study identified low pH condition (encountered in many tumors) as an exquisite environment that favors tumor-selective production of $\mathrm{NO}$ in response to nitrite systemic injection. This work opens new perspectives for the use of nitrite as a safe and clinically applicable radiosensitizing modality.
\end{abstract}

Nitric oxide (NO), one of the smallest biologically active molecules, plays a major role in many key pathophysiologic processes including the control of vascular tone (1) and angiogenesis (2). Although nitrites $\left(\mathrm{NO}_{2}^{-}\right)$have been described

Authors'Affiliations: Unit of ${ }^{1}$ Pharmacology and Therapeutics, Université catholique de Louvain, UCL-FATH and ${ }^{2}$ Biomedical Magnetic Resonance, Université catholique de Louvain, UCL-REMA, Brussels, Belgium; and ${ }^{3}$ Laboratory of Tumor and Developmental Biology, University of Liège, Tour de Pathologie (B23), Sart-Tilman, Belgium Received 8/22/07; revised 11/18/07; accepted 12/11/07.

Grant support: Fonds de la Recherche Scientifique Médicale, the Fonds national de la Recherche Scientifique, the Télévie, the Belgian Federation Against Cancer, the J. Maisin Foundation, an Action de Recherche Concertée (ARC 04/09-317) from the Communauté Française de Belgique and the NeoAngio program (Région wallonne). The costs of publication of this article were defrayed in part by the payment of page charges. This article must therefore be hereby marked advertisement in accordance with 18 U.S.C. Section 1734 solely to indicate this fact.

Note: F. Frérart and P. Sonveaux contributed equally to this work. O. Feron and C. Dessy are Fonds national de la Recherche Scientifique Senior Research Associates. P. Sonveaux and B.F. Jordan are Fonds national de la Recherche Scientifique postdoctoral researchers.

Requests for reprints: Olivier Feron, Unit of Pharmacology and Therapeutics, University of Louvain, UCL-FATH 5349, 52 Avenue E. Mounier, B-1200 Brussels, Belgium. Phone: 32-2-764-5264; Fax: 32-2-764-5269; E-mail: olivier.feron@ uclouvain.be.

(C) 2008 American Association for Cancer Research.

doi:10.1158/1078-0432.CCR-07-4001 for a long time, with nitrates, as the inert end products of the $\mathrm{NO}$ oxidative metabolism (3), recent evidence indicates that under specific conditions, nitrite can be reconverted into biologically active NO (4). The nitrite anion is now considered as the largest intravascular and tissue storage of $\mathrm{NO}$, which may be made available depending on the tissue need. Nitrite was, for instance, shown to contribute to hypoxic vasodilation, i.e., a conserved systemic physiologic response that matches blood flow and oxygen delivery to tissue metabolic demand (5-7). Accordingly, several investigators showed that nitrite infusion could protect several organs, including heart, liver, kidney, and brain from ischemia-reperfusion injuries $(8-13)$.

Different enzymatic and nonenzymatic pathways are proposed to support the reductive reconversion of nitrite into NO. Heme-containing enzymes including hemoglobin $(7,14,15)$ and xanthine oxidase $(16,17)$ may act as nitrite reductases and/or $S$-nitrosothiol synthases under hypoxia, thereby offering a salvage pathway to produce $\mathrm{NO}$ when the $\mathrm{O}_{2}$-consuming NO synthases become inoperative; endothelial NO synthase itself in the absence of oxygen may behave as a nitrite reductase (18). The nonenzymatic pathway for nitrite reconversion to NO requires another peculiarity of the microenvironment, namely a reduced $\mathrm{pH}$, to favor the acidic reduction (disproportionation) of nitrite species $(19-21)$. This is best exemplified in the stomach where the very low $\mathrm{pH}$ promotes the conversion of the high concentrations of nitrite present in saliva (derived from 
dietary nitrate) to $\mathrm{NO}$ and other nitrogen oxides to provide protection from swallowed pathogens (22) and enhance blood flow in the gastric mucosa (23).

Because acidic $\mathrm{pH}$ is a specificity of many tumors $(24-26)$, although to a much lesser extent than in stomach, one may hypothesize that nitrite could represent an important source of bioactive NO in tumors and/or that infusion of nitrite could preferentially produce a local burst of NO in tumors (versus host tissues at physiologic $\mathrm{pH}$ ). The therapeutic potential of an acute production of NO in tumors is huge as, by driving local vasodilation and increasing perfusion, NO may transiently increase the delivery of drugs into the tumor and correct hypoxia, thereby improving the efficacy of ionizing radiations. Moreover, these latter effects might be exacerbated by the intrinsic radiosensitizing effects of NO (27) and its capacity to inhibit mitochondrial respiration, thereby further increasing intracellular $\mathrm{O}_{2}$ levels $(28,29)$.

In this study, we provide the proof of concept that nitrite may selectively induce a transient increase in tumor partial $\mathrm{O}_{2}$ pressure $\left(\mathrm{pO}_{2}\right)$, which may be exploited to improve the efficacy of radiotherapy. The effects of nitrite were identified to be attributable not to an increase in tumor blood flow but to a reduction in the $\mathrm{O}_{2}$ consumption rate of tumor cells. Based on this work, nitrite can be viewed as a promising, safe, and inexpensive adjuvant modality to antitumor strategies, particularly radiotherapy.

\section{Materials and Methods}

Mice and tumor cells. Male Rj:NMRI mice received an i.m. injection of $10^{6}$ syngeneic (TLT) transplantable liver tumor hepatocarcinoma cells in the posterior right leg at the vicinity of the saphenous arteriole (i.e., the vessel used for ex vivo vasorelaxation assay; see below), as previously described $(30,31)$. The tumor diameters were tracked with an electronic caliper. When the tumor diameter reached $4.0 \pm 0.5 \mathrm{~mm}$, mice were randomly assigned to a treatment group. Nitrite $\left(\mathrm{NaNO}_{2}\right)$ or saline was injected through the catheterized tail vein of anesthetized mice. Each procedure was approved by the local authorities according to national animal care regulations. Transplantable liver tumor TLT carcinoma cells were maintained in culture in DMEM containing 10\% FCS.

Videomotion analysis of vessel relaxation. Saphenous and mesenteric arterioles were dissected under a stereoscopic microscope and processed as previously described $(31,32)$. Briefly, vessels were mounted in a Plexigas isolated organ chamber circulated with oxygenated physiologic saline solution $\left(37^{\circ} \mathrm{C}\right)$ and placed on an inverted microscope (Axiovert S100; Zeiss) connected to a charge-coupled device camera. Vessels were then pressurized with a physiologic saline solution-filled burette manometer at $60 \mathrm{mmHg}$. Digitized imaging (Ionoptix) allowed continuous monitoring of vessel external diameter. Arterioles were precontracted with a $\mathrm{KCl}$ solution and were then exposed, at the indicated level of $\mathrm{pH}$ (6.8 or 7.4), to increasing concentrations of nitrite, in the presence (or not) of $1 \mathrm{H}-[1,2,4]$ Oxadiazolo[4,3-a]quinoxalin-1-one (ODQ), L-NAME, or allopurinol; all the treatments were added in the bathing solution.

Tumor oxygenation monitoring. Electronic paramagnetic resonance (EPR) oximetry, using charcoal (CX0670-1; EM Science) as the oxygensensitive probe, was used to evaluate tumor and muscle oxygenation as previously described (33). EPR spectra were recorded using an EPR spectrometer (Magnettech) with a low frequence microwave bridge operating at $1.2 \mathrm{GHz}$ and extended loop resonator. Data acquisition was started before nitrite administration; each mouse was used as its own control.

Tumor blood flow monitoring. Tumor blood flow was measured with a Laser Doppler imager (Moor Instruments), which maps cortical tumor perfusion (with a tissue penetration of $\sim 2 \mathrm{~mm}$ ), and with Laser Doppler microprobes (OxyFlo; Oxford Optronix). For the Laser Doppler measurements, mice were anesthetized and fur was removed from the limbs using a depilatory cream. Perfusion of the tumorbearing and control legs was evaluated on the basis of colored histogram pixels. For OxyFlo measurements, fiberoptic microprobes were inserted into the tumor and into the opposite (healthy) leg. Data were collected continuously at a sampling frequency of $20 \mathrm{~Hz}$. For both assays, the animals were placed on a heating pad $\left(37^{\circ} \mathrm{C}\right)$ to minimize variations in temperature and a 10-min stable recording baseline was acquired before treatment administration through the catheterized tail vein (to validate the absence of movement artifacts).

Oxygen consumption rate evaluation. Tumor cells were trypsinized, centrifuged, and resuspended in buffered saline solution at $\mathrm{pH} 7.4$ or 6.7. An aliquot of $2.10^{6}$ cells was incubated for $15 \mathrm{~min}$ in the presence of $100 \mu \mathrm{mol} / \mathrm{L}$ nitrite before the addition of $20 \%$ dextran and neutral nitroxide (an oxygen sensitive probe), ${ }^{15} \mathrm{~N}$ 4-oxo-2,2,6,6-tetramethylpiperidine- $\mathrm{d}_{16^{-}}{ }^{15} \mathrm{~N}$-1-oxyl at $0.2 \mathrm{mmol} / \mathrm{L}$ (CDN Isotopes). The suspension was drawn into glass capillary tubes; cytotoxicity was concomitantly evaluated with a 3-(4,5-dimethylthiazole-2-yl)-2,5diphenyl tetrazolium bromide (MTT) assay (34). All spectra were recorded on a Bruker EMX EPR spectrometer operating at $9 \mathrm{GHz}$, as previously described (33). The probe was calibrated at various $\mathrm{O}_{2}$ concentrations between $100 \%$ nitrogen and air so that the line width measurements were related to $\mathrm{O}_{2}$ concentration at any value. Nitrogen

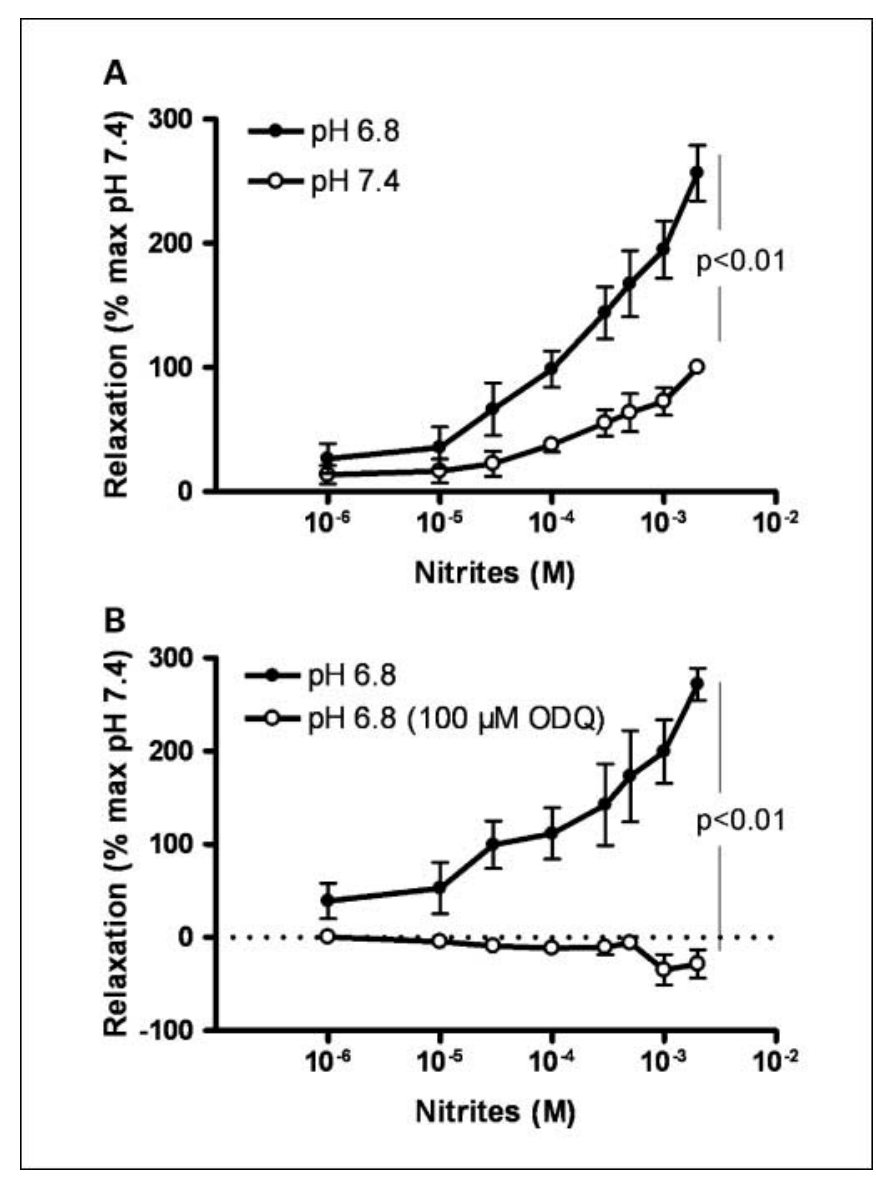

Fig. 1. Nitrite induces vasodilation in a $\mathrm{pH}$ - and $\mathrm{NO}$-dependent manner. $A$, arterioles were mounted on a pressure myograph, precontracted to restore the vascular tone, and exposed to increasing doses of nitrite. $A$, vasodilating response to nitrite obtained at $\mathrm{pH} 7.4(O)$ or $6.8(\bullet ; n=6)$. $B$, effect of the guanyl cyclase inhibitor ODQ $(100 \mu \mathrm{mol} / \mathrm{L} ; \mathrm{O})$ on the vasodilating response to nitrite at pH $6.8(n=3)$; the effect of the vehicle treatment is also shown $(\bullet ; n=3)$. Vasorelaxation is expressed as \% (mean $\pm \mathrm{SE}$ ) of the maximal response observed at $\mathrm{pH} 7.4$ ( $P<0.01 ; n$, number of arterioles per condition). 


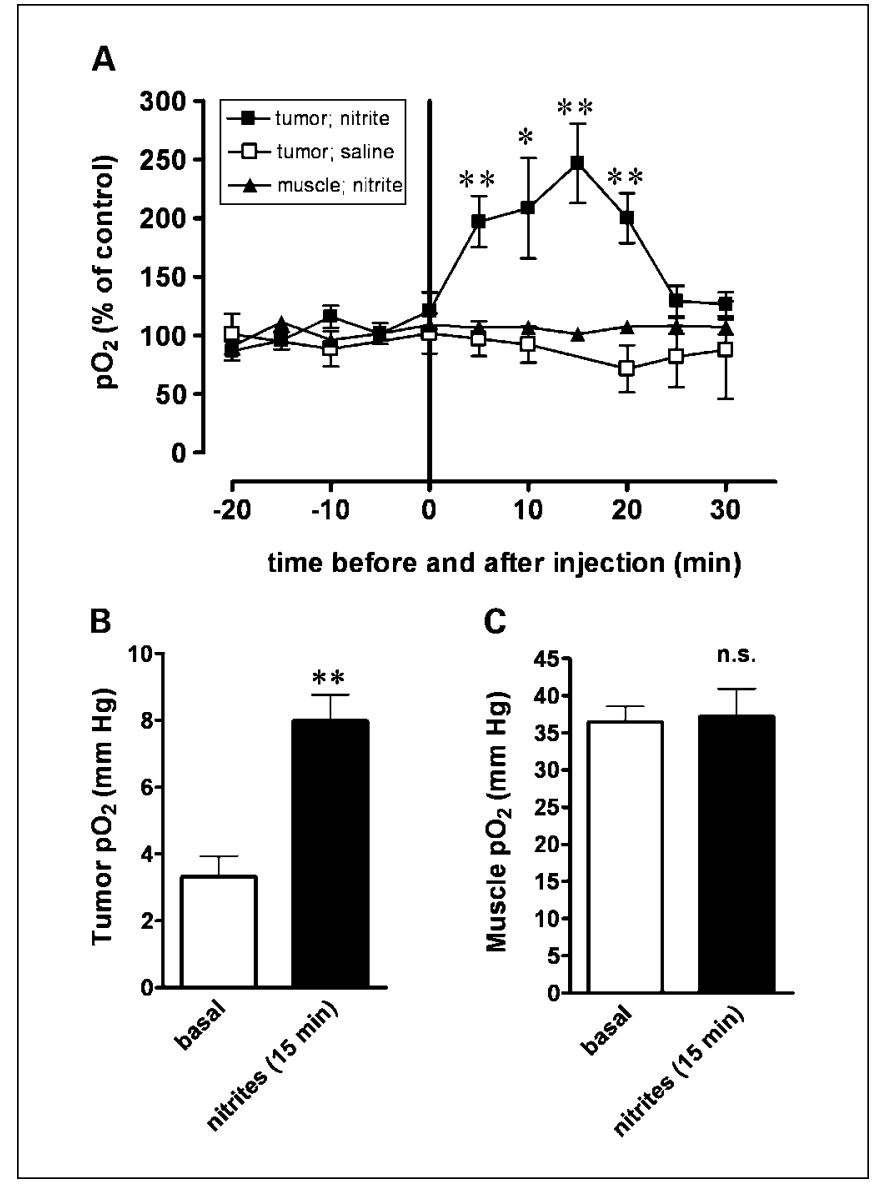

Fig. 2. Nitrite i.v. injection induces a robust, transient, and tumor-specific increase in oxygenation. Tumor-bearing mice were i.v. injected with a $5 \mathrm{mmol} / \mathrm{L}$ nitrite solution (final blood concentration, $\sim 100 \mu \mathrm{mol} / \mathrm{L}$ ), and $\mathrm{pO}_{2}$ was determined by EPR oximetry in the tumor (implanted in the right leg) and in the muscle (of the contralateral leg). $A$, tumor $(\boldsymbol{\square} ; n=8)$ and muscle $(\boldsymbol{\Delta} ; n=5) \mathrm{pO}_{2}$ before and after the injection (at $\mathrm{t}=0$ ); the effect of a saline injection on the tumor $\mathrm{pO}_{2}$ is also shown as control $(\square ; n=4)$. Results are expressed as $\%$ (mean $\pm \mathrm{SE}$ ) of basal $\mathrm{pO}_{2}$ levels $\left({ }^{*}, P<0.05 ;{ }^{* *}, P<0.01 ; n\right.$, number of mice per condition). $B$ to $C$, mean $( \pm \mathrm{SE}) \mathrm{pO}_{2}$ (expressed in $\mathrm{mmHg}$ ) as determined in tumor $(B)$ and muscle $(C)$, before (white bars) and $15 \mathrm{~min}$ after i.v. injection of nitrite (black bars; ${ }^{* *}, P<0.01$; n.s., nonsignificant; $n=4-8$ mice per condition); note that different $Y$-axis scales are used in $B$ and $C$.

and air were mixed in an Aalborg gas mixer, and the oxygen concentration was analyzed using a Servomex oxygen analyzer OA540. The sealed tubes were placed into quartz EPR tubes maintained at $37^{\circ} \mathrm{C}$, and the $\mathrm{O}_{2}$ levels were determined over time.

Irradiation and tumor growth delay assay. Anesthetized tumorbearing mice were i.v. injected with saline or nitrite solutions $10 \mathrm{~min}$ before being locally irradiated using a RT-250 device (Philips Medical Systems) with a dose delivery of $0.76 \mathrm{~Gy} / \mathrm{min}$. The tumor was centered in a circular irradiation field, and healthy tissues were protected by a lead mask. After treatment, tumor diameters and mouse survival were tracked daily.

Statistical analyses. Data are reported as mean $\pm \mathrm{SE}$, and statistical analyses were done using Student's $t$ test, two-way ANOVA analyses, or Log-rank test where appropriate.

\section{Results}

Nitrite induces arteriole dilation in a $\mathrm{pH}$ - and NO-dependent manner. We first aimed to determine whether bioactive NO could be produced from nitrite in response to a small drop in
$\mathrm{pH}$ (as observed in tumors). For that purpose, we examined the response of arterioles (from the vascular bed wherein tumors are established in our mouse model) to nitrite administration. Arterioles (mean diameter, $\sim 250 \mu \mathrm{m}$ ) were microdissected and mounted in a pressure myograph. Figure 1A shows that nitrite dose-dependently induced the relaxation of the arterioles both at physiologic and acidic $\mathrm{pH}$ (7.4 and 6.8, respectively). Interestingly, the maximal relaxation observed at $\mathrm{pH} 6.8$ amounted to 2.5-fold to that obtained at $\mathrm{pH}$ 7.4. To further examine whether nitrite-driven vasodilation was due to the activation of the NO/cyclic guanosine $3^{\prime}, 5^{\prime}$-monophosphate pathway, we repeated the experiments at $\mathrm{pH} 6.8$ in the presence of $100 \mu \mathrm{mol} / \mathrm{L}$ ODQ, a pharmacologic inhibitor of the soluble guanyl cyclase. Figure $1 \mathrm{~B}$ shows that ODQ completely prevented the nitrite-induced relaxation of the arteriole,

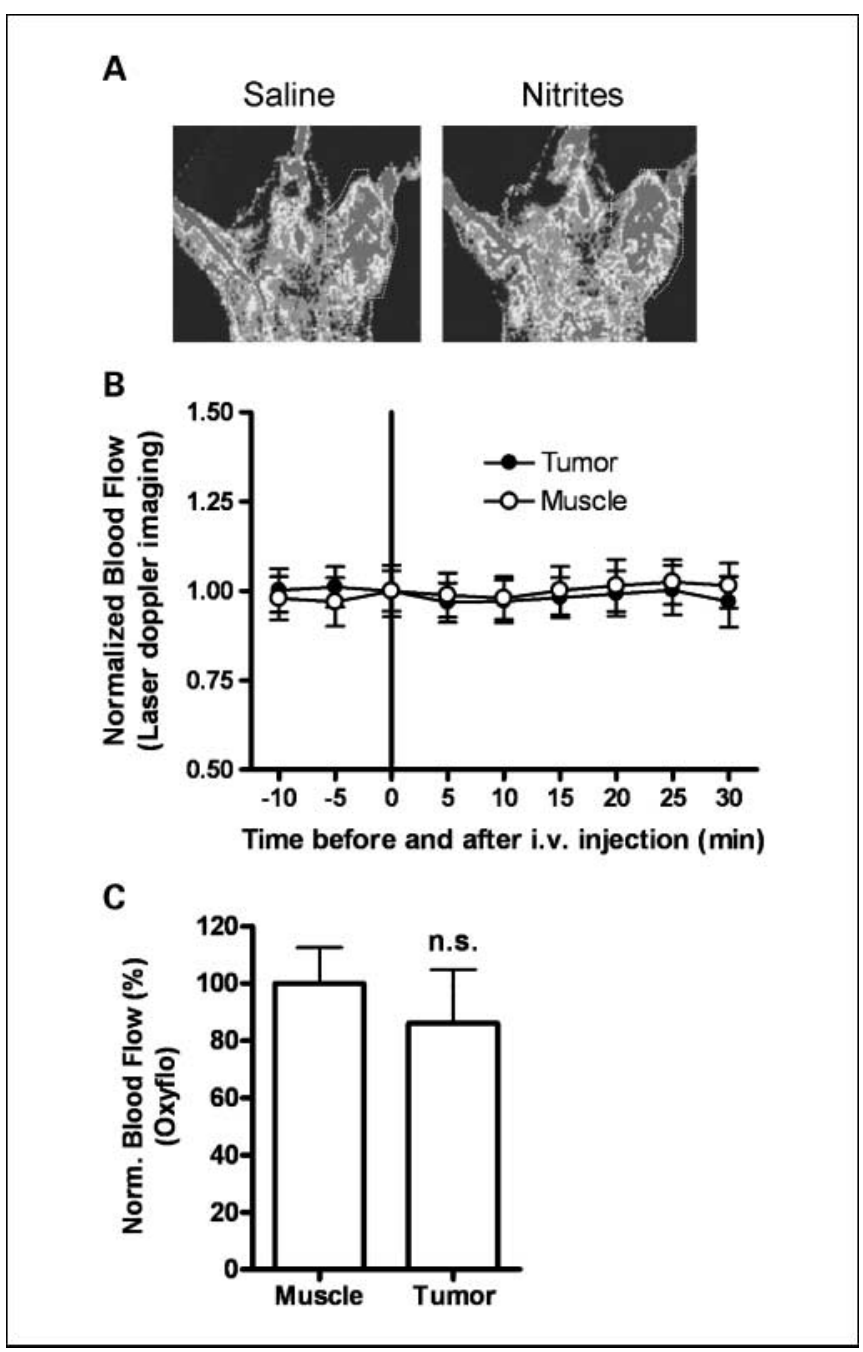

Fig. 3. Nitrite injection does not alter tumor blood flow. Tumor-bearing mice were i.v. injected with nitrite or saline (as described in Fig. 2), and blood flow was measured in tumor and healthy muscle. $A$, representative pictures from laser Doppler imaging obtained 15 min after nitrite injection; the zone corresponding to the tumor is surrounded by a dotted line. $B$, evolution of blood flow determined by laser Doppler imaging, simultaneously, in tumor $(\bullet)$ and muscle $(O)$ before and after the nitrite injection (at $\mathrm{t}=0$ ). Data are expressed as $\%$ (mean $\pm \mathrm{SE}$ ) of the basal blood flow measured after saline injection $(n=6)$. $C$, blood flow in tumor and muscle determined by Oxyflo microprobes 15 min after the i.v. injection of nitrite. Data are expressed as \% (mean \pm SE) of the basal blood flow measured in the muscle ( $n=5$ mice per condition). 
Fig. 4. Nitrite reduces tumor cell oxygen consumption at acidic $\mathrm{pH}$. Graphs represent the tumor cell $\mathrm{O}_{2}$ consumption rate after exposure to a $100 \mu \mathrm{mol} / \mathrm{L}$ nitrite solution $(\boldsymbol{E})$ or a saline solution $(\square)$ at $\mathrm{pH} 7.4(A)$ and $6.7(B)$, as measured by EPR oximetry. Data (mean $\pm \mathrm{SE}$ ) are expressed as \% of $\mathrm{O}_{2}$ detected in the sealing tubes ( $n=3-5$; different cell pools); lack of overall cytotoxicity was verified in MTTassays (inset). $C$, slope values (mean $+\mathrm{SE}$ ) of linear regressions presented in $A$ and $B$ are presented $(* *, P<0.01)$.

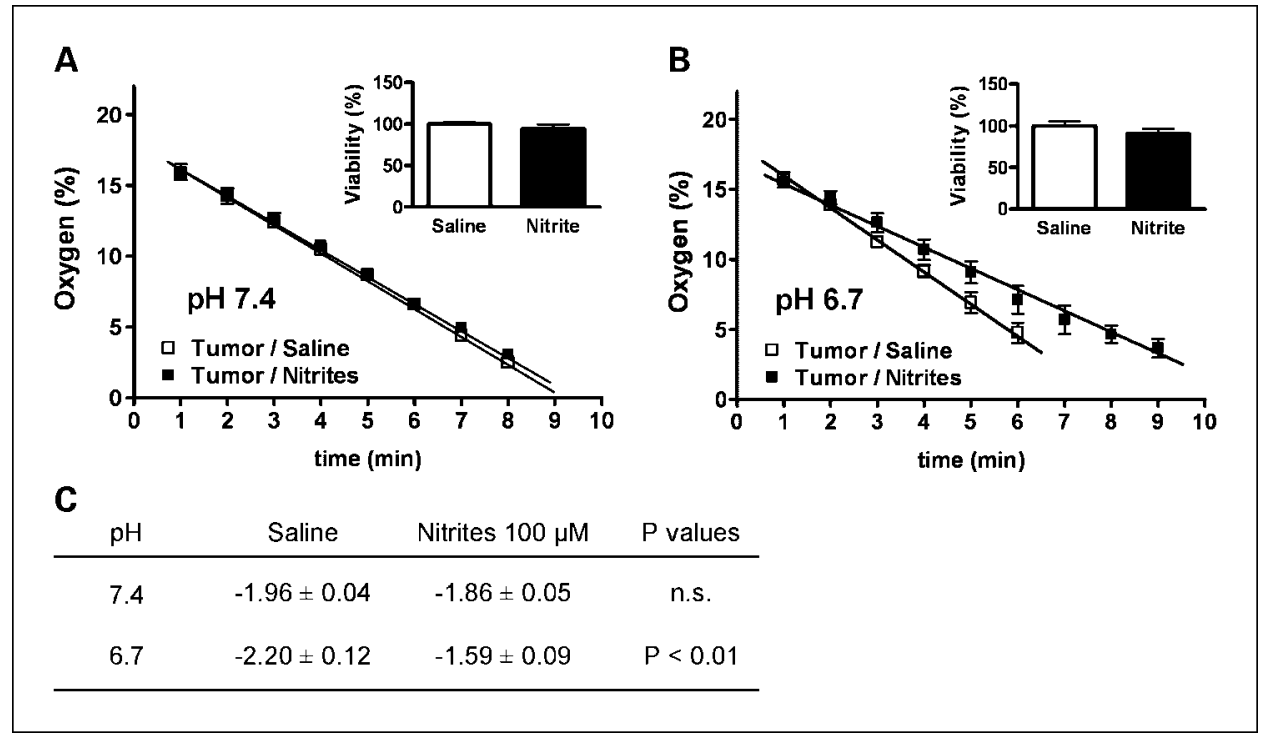

confirming implication of NO. To address the role of NO synthase and xanthine oxidase as possible enzymatic sources of nitrite reductase, these experiments were repeated in the presence of the specific pharmacologic inhibitors, L-NAME and allopurinol, respectively. These inhibitors failed to alter nitrite-induced vasorelaxation at both $\mathrm{pH}$ values (data not shown).

Nitrite i.v. administration induces a robust, transient, and tumor-selective increase in oxygenation. To evaluate a possible role of nitrite in vivo, we used EPR to determine changes in local $\mathrm{pO}_{2}$ in a highly glycolytic mouse tumor model. Figure $2 \mathrm{~A}$ shows that tail vein injection of nitrite (final blood concentration, $\sim 100 \mu \mathrm{mol} / \mathrm{L}$ ) led to a net increase in tumor $\mathrm{pO}_{2}$ but failed to induce any changes in the (tumor free) contralateral limb muscle. Saline injection to tumor-bearing mice was also used as control and did not reveal any alteration in the tumor $\mathrm{pO}_{2}$ (Fig. $2 \mathrm{~A}$ ).

The effect of nitrite on tumor $\mathrm{pO}_{2}$ was transient, peaking at 2.5-fold of the basal level after 15 minutes and back to normal after 30 minutes. The absolute numbers (see Fig. 2B) indicate that the temporary shift in $\mathrm{pO}_{2}$ from $3.3 \pm 0.6$ to $8.0 \pm 0.8$ $\mathrm{mmHg}$ is in the range generally admitted to lead to radiosensitizing effects (35). In the muscle, the $\mathrm{pO}_{2}$ was much higher $(\sim 35 \mathrm{mmHg})$ and not influenced by nitrite administration (Fig. 2C).

Nitrite administration does not alter tumor blood flow. We then sought to verify whether the effects of nitrite on $\mathrm{pO}_{2}$ could be attributed to an increase in tumor perfusion. We first used laser Doppler imaging to monitor blood flow at the surface of the tumor, where the microcirculation is the most developed in this tumor model (data not shown). Figure 3A shows that administration of nitrite (at the same concentration as used in Fig. 2) failed to induce any change in tumor (and muscle) perfusion. Normalization of the blood flow values confirmed that nitrite did not alter perfusion neither in the tumor, nor in the muscle when compared with a saline injection (Fig. 3B). We also used Oxyflo microprobes to monitor blood flow deeper in the tumor. Again, this more invasive technique failed to reveal significant alterations in the tumor (and muscle) perfusion in response to nitrite administration (Fig. 3C).
Nitrite exposure decreases tumor cell oxygen consumption rate at acidic pH. As a change in tumor blood flow could not account for the observed increase in tumor $\mathrm{pO}_{2}$, we then examined whether the consumption of $\mathrm{O}_{2}$ could differ in tumor cells exposed to nitrite. Tumor cells were isolated and placed in a sealed tube with nitrite, and respiration was monitored with a EPR oxygen-sensitive probe. We found that the rate of oxygen consumption was unaltered by the presence of nitrite when cells were bathed in a medium at $\mathrm{pH} 7.4$ (Fig. 4A), whereas the respiration was significantly slowed down when the medium was buffered at pH 6.7 (Fig. 4B). Slope analysis revealed that the oxygen consumption rate under these mild acidic conditions was 38\% smaller in the presence of nitrite (Fig. 4C). We also verified that in these experimental conditions, cell viability was not altered by the addition of nitrite (Fig. 4A and $\mathrm{B}$, insets).

A single nitrite administration radiosensitizes tumor. Finally, to validate the therapeutic effect of the reduction in $\mathrm{O}_{2}$ consumption (i.e., the local increase in tumor $\mathrm{pO}_{2}$ ), we locally irradiated tumor-bearing mice 15 minutes after i.v. administration of nitrite. Figure $5 \mathrm{~A}$ shows that the combination of nitrite and a 6 Gy radiation dose significantly improved mouse survival. Importantly, nitrite alone did not effect tumor growth, even when administered at a 10-fold higher concentration. Determination of the tumor growth doubling time revealed that whereas radiotherapy alone delayed this variable by 2 days, the combination of irradiation and nitrite extended this time to 5.5 days, increasing by almost 2 -fold the absolute doubling time value determined in saline-treated mice (Fig. 5B).

\section{Discussion}

The major findings of this study are the demonstration of a tumor-selective increase in $\mathrm{pO}_{2}$ in response to a bolus systemic administration of nitrite and the proof of concept that such a procedure is therapeutically exploitable to radiosensitize tumors. Moreover, we have identified tumor cell respiration but not tumor perfusion as a critical target of nitrite, and low $\mathrm{pH}$, as encountered in many tumor types, as a necessary condition to promote the nitrite conversion into bioactive NO. 
A

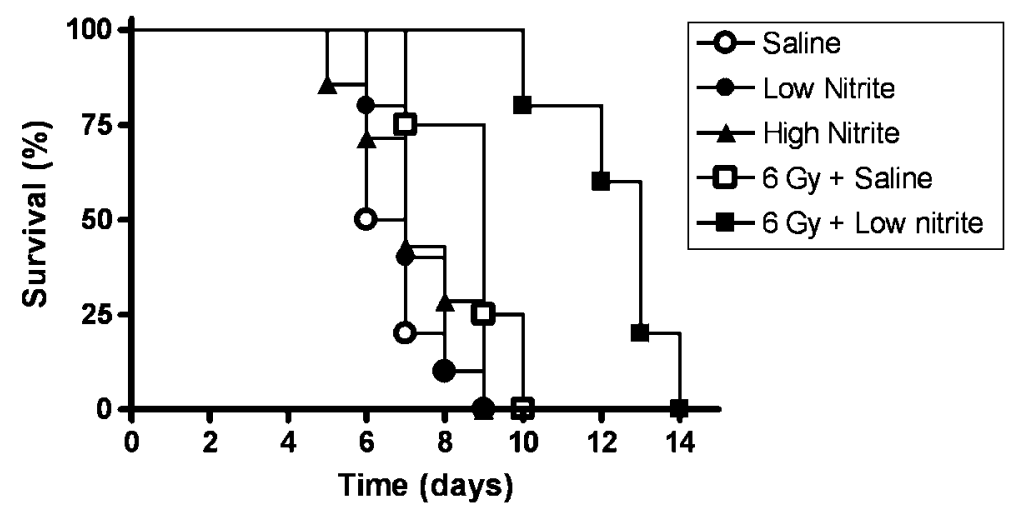

B

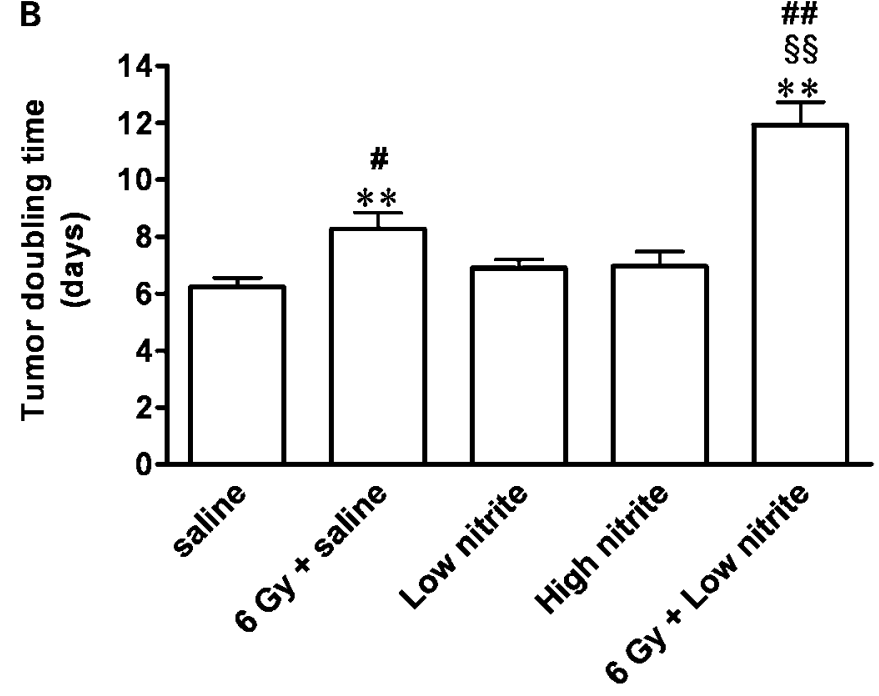

Fig. 5. Nitrite i.v. injection radiosensitizes tumor $A$, Kaplan-Meier survival curves depicting the effects of low and high doses of nitrite $[100 \mu \mathrm{M}(\mathbf{0} ; n=10)$ and $2 \mathrm{mmol} / \mathrm{L}(\boldsymbol{\Delta} ; n=5)$, respectively], radiotherapy $(6 G y)+$ saline $(\square ; n=5)$ or a combination of radiotherapy and low dose of nitrite (administered 15 min before irradiation; $\mathbf{\square} ; n=5)$; the effect of saline injection $(0 ; n=10)$ is also shown as control. Data are expressed as \% of mouse survival $\left({ }^{*}, P<0.05\right.$ and ${ }^{* *}, P<0.01$ versus saline; \#, $P<0.05$ and \#\#, $P<0.01$ versus low dose of nitrite; $\S \S$, $P<0.01$ versus radiotherapy + saline; $n=$ number of mice per condition). $B$, tumor doubling time (mean $\pm \mathrm{SE}$ ) in the same groups as in $\left(A ;{ }^{* *}, P<0.01\right.$ versus saline; \#, $P<0.05$ and \#\#, $P<0.01$ versus low dose of nitrite; $\delta \S$ $P<0.01$ versus radiotherapy + saline $)$.
We found that both vascular and tumor cells may be influenced by nitrite exposure to a larger extent under acidic conditions than at physiologic $\mathrm{pH}$. The same dose of nitrite (100 $\mu \mathrm{mol} / \mathrm{L})$ showed, for instance, a 3-fold higher capacity to dilate isolated arterioles (Fig. 1A) and a reduction in tumor cell $\mathrm{O}_{2}$ consumption by $\sim 40 \%$ (Fig. $4 \mathrm{~B}$ ) when the $\mathrm{pH}$ was set at 6.7 to 6.8 (versus $\mathrm{pH} 7.4$ ). Together with the observation that a blocker of the NO/cyclic guanosine $3^{\prime}, 5^{\prime}$-monophosphate pathway prevented these effects, our results authenticate the acidic environment as a key variable to favor nitrite reconversion into NO. Interestingly, however, although we observed an increase in tumor $\mathrm{pO}_{2}$ after a bolus i.v. administration of nitrite in vivo, we failed to detect any effects of nitrite on the tumor blood flow using superficial and invasive methods of measurements. The balance between oxygen delivery and oxygen consumption implies that the nitrite-driven increase in tumor $\mathrm{pO}_{2}$ is attributable to the consumption arm of the equation, i.e., to the inhibition of mitochondrial respiration (as observed in vitro). Inhibitory effects of $\mathrm{NO}$ on cell respiration were previously reported to mainly arise from the nitrosylation and consecutive inhibition of the cytochrome $c$ oxidase and complex I within the mitochondrial respiratory chain (28).

The absence of alterations in the tumor cell respiration measured in vitro at physiologic $\mathrm{pH}$ emphasizes the critical role of acidity in driving the nitrite effects. Although blood flow removes waste products of the tumor cell metabolism, including lactic acid, thereby creating in vivo an acidity gradient from the blood vessels toward the surrounding tumor mass, such gradient is buffered in vitro by "normal" culture medium. It should be noted however that the small drop in pH (less than one $\mathrm{pH}$ unit; refs. 24-26) generally observed in tumors (including in highly glycolytic tumors as used in this study) is by far less pronounced than in the stomach where the continuous delivery of saliva-containing nitrite allows the production of bacteriostatic NO. Reducing equivalents particularly abundant in tumor cells (36) are therefore likely to play an important role in the local production of NO from nitrite. Interestingly, Zweier and colleagues (37) reported that the addition of an aliquot of ischemic tissue homogenates to nitrite in the presence of a low $\mathrm{pH}$ led to a dramatic increase in the rate of NO generation.

Hemoglobin was identified by several authors to act as a transporter and provider of $\mathrm{NO} / \mathrm{NO}$ derivatives through either direct $S$-nitrosylation (including by nitrite) and consecutive release of nitrosothiols (38) or through a direct interaction of nitrite with deoxyhemoglobin, which may release NO in regions of poor oxygenation $(39,40)$. These effects of hemoglobin were documented to favor vasorelaxation and 
thereby to help redistributing blood flow to ischemic regions of greatest need. In our experiments, the absence of changes in tumor and muscle blood flow indicates that such role of hemoglobin in driving the blood conversion of nitrite into NO is limited or at least counterbalanced by the NO-scavenging capacity of oxyhemoglobin and deoxyhemoglobin (41). A role of NO in modifying the affinity of hemoglobin for $\mathrm{O}_{2}(7)$ can however not be excluded in our experimental conditions and certainly warrants further investigation. By contrast, the incapacity of pharmacologic inhibitors of xanthine oxidase and NO synthase (allopurinol and L-NAME, respectively) to prevent nitrite effects allows us to reasonably rule out a major role of these two main tissue enzymes endowed with a nitrite reductase activity.

The clinical potential of using nitrite as a strategy to sensitize tumor cells to radiotherapy is huge. First, the acidic microenvironment is a hallmark of many tumors, making this treatment modality applicable to a large variety of cancers. Furthermore, the effects of a bolus administration of nitrite are transient and occur rapidly. The 30-minute window of increased $\mathrm{pO}_{2}$ with the peaking value around 15 minutes may be conveniently anticipated before irradiation. Second, the strategy is inexpensive and if validated in clinical trials, could be applied as a standard clinical procedure. Third, and not least, the administration of nitrite seems as a safe approach with a favorable hazard/benefit ratio. As indicated above, the transient and tumor-selective nature of the NO burst needs to be distinguished from a sustained production of high amounts NO and the associated mutagenic effects (as observed in response to inducible NOS expression during chronic inflammation; ref. 42). In fact, considering the rate of nitrite reconversion into $\mathrm{NO}$ at $\mathrm{pH} 6.7$ (19), the maximum concentration of NO that could be generated in our experimental conditions remains in the nanomolar range. It is also worthy to note that different authors have reported the safe administration of nitrite in mice and rats suffering from cardiovascular diseases. Data in nonrodent animals and humans are also available. For instance, Pluta and colleagues (43) reported that sodium nitrite infusion prevented delayed cerebral vasospasm in a primate model of subarachnoid hemorrhage without clinical or pathologic evidence of toxicity. Cosby and colleagues (39) reported that nitrite infusion into the human forearm brachial artery resulted in increased blood flow before and during exercise. It should also be mentioned that nitrite is historically used as a treatment for cyanide poisoning (44).

In conclusion, our study shows that the small reduction in $\mathrm{pH}$ values (versus physiologic $\mathrm{pH}$ ) as encountered in the extracellular medium of many tumors is sufficient to produce large amounts of bioactive NO in response to a systemic bolus nitrite injection. The consecutive increase in tumor $\mathrm{pO}_{2}$ may translate in a tumor-selective, safe, and inexpensive therapeutic strategy to sensitize tumors to radiotherapy.

\section{Disclosure of Potential Conflicts of Interest}

No potential conflicts of interest were disclosed.

\section{References}

1. Moncada S, Higgs A, Furchgott R. International Union of Pharmacology Nomenclature in Nitric Oxide Research. Pharmacol Rev 1997;49:137-42.

2. Morbidelli L, Donnini S, Ziche M. Role of nitric oxide in the modulation of angiogenesis. Curr Pharm Des 2003:9:521-30.

3. Ignarro LJ, Fukuto JM, Griscavage JM, Rogers NE, Byrns RE. Oxidation of nitric oxide in aqueous solution to nitrite but not nitrate: comparison with enzymatically formed nitric oxide from L-arginine. Proc Natl Acad Sci U S A 1993;90:8103-7.

4. Gladwin MT, Schechter AN, Kim-Shapiro DB, et al. The emerging biology of the nitrite anion. Nat Chem Biol 2005;1:308-14.

5. Singel DJ, Stamler JS. Chemical physiology of blood flow regulation by red blood cells: the role of nitric oxide and S-nitrosohemoglobin. Annu Rev Physiol 2005;67:99-145.

6. Crawford JH, Isbell TS, Huang Z, et al. Hypoxia, red blood cells, and nitrite regulate NO-dependent hypoxic vasodilation. Blood 2006;107:566-74.

7. Sonveaux P, Lobysheva II, Feron O, McMahon TJ. Transport and peripheral bioactivities of nitrogen oxides carried by red blood cell hemoglobin: role in oxygen delivery. Physiology Bethesda 2007;22: 97-112.

8. Zweier JL, Wang P, Samouilov A, Kuppusamy P. Enzyme-independent formation of nitric oxide in biological tissues. Nat Med 1995;1:804-9.

9. Webb A, Bond R, McLean P, Uppal R, Benjamin N, Ahluwalia A. Reduction of nitrite to nitric oxide during ischemia protects against myocardial ischemia-reperfusion damage. Proc Natl Acad Sci U S A 2004;101: 13683-8.

10. Duranski MR, Greer JJ, Dejam A, et al. Cytoprotective effects of nitrite during in vivo ischemia-reperfusion of the heart and liver. J Clin Invest 2005;115: $1232-40$.
11. Lu P, Liu F, Yao Z, et al. Nitrite-derived nitric oxide by xanthine oxidoreductase protects the liver against ischemia-reperfusion injury. Hepatobiliary Pancreat Dis Int 2005;4:350-5

12. Tripatara $P$, Patel NS, Webb $A$, et al. Nitritederived nitric oxide protects the rat kidney against ischemia/reperfusion injury in vivo: role for xanthine oxidoreductase. J Am Soc Nephrol 2007; 18:570-80.

13. Jung $\mathrm{KH}, \mathrm{Chu} \mathrm{K}$, Ko SY, et al. Early intravenous infusion of sodium nitrite protects brain against in vivo ischemia-reperfusion injury. Stroke 2006; $37: 2744-50$.

14. Shiva S, Huang Z, Grubina R, et al. Deoxymyoglobin is a nitrite reductase that generates nitric oxide and regulates mitochondrial respiration. Circ Res 2007; 100:654-61.

15. Angelo M, Singel DJ, Stamler JS. An S-nitrosothiol (SNO) synthase function of hemoglobin that utilizes nitrite as a substrate. Proc Natl Acad Sci U S A 2006; 103:8366-71.

16. Millar TM, Stevens CR, Benjamin N, Eisenthal R, Harrison R, Blake DR. Xanthine oxidoreductase catalyses the reduction of nitrates and nitrite to nitric oxide under hypoxic conditions. FEBS Lett 1998; 427:225-8.

17. Godber BL, Doel JJ, Sapkota GP, et al. Reduction of nitrite to nitric oxide catalyzed by xanthine oxidoreductase. J Biol Chem 2000;275:7757-63.

18. Vanin AF, Bevers LM, Slama-Schwok $A$, van Faassen EE. Nitric oxide synthase reduces nitrite to NO under anoxia. Cell Mol Life Sci 2007;64: 96-103.

19. Zweier JL, Samouilov A, Kuppusamy P. Nonenzymatic nitric oxide synthesis in biological systems. Biochim Biophys Acta 1999;1411:250-62.

20. Modin A, Bjorne H, Herulf M, Alving K, Weitzberg E, Lundberg JO. Nitrite-derived nitric oxide: a possible mediator of 'acidic-metabolic' vasodilation. Acta Physiol Scand 2001;171:9-16

21. Lundberg JO, Weitzberg E. NO generation from nitrite and its role in vascular control. Arterioscler Thromb Vasc Biol 2005;25:915-22.

22. Benjamin N, O'Driscoll F, Dougall $H$, et al. Stomach NO synthesis. Nature 1994;368:502.

23. Bjorne $\mathrm{HH}$, Petersson J, Phillipson M, Weitzberg $E$, Holm L, Lundberg JO. Nitrite in saliva increases gastric mucosal blood flow and mucus thickness. J Clin Invest 2004;113:106-14.

24. Gerweck LE, Seetharaman K. Cellular pH gradient in tumor versus normal tissue: potential exploitation for the treatment of cancer. Cancer Res 1996;56 1194-8.

25. Gillies RJ, Raghunand N, Karczmar GS, Bhujwalla ZM. MRI of the tumor microenvironment. J Magn Reson Imaging 2002;16:430-50.

26. Swietach $P$, Vaughan-Jones RD, Harris AL. Regulation of tumor $\mathrm{pH}$ and the role of carbonic anhydrase 9 . Cancer Metastasis Rev 2007;26:299-310.

27. Jordan BF, Sonveaux $P$, Feron $O$, et al. Nitric oxide as a radiosensitizer: evidence for an intrinsic role in addition to its effect on oxygen delivery and consumption. Int J Cancer 2004;109:768-73.

28. Clementi E, Brown GC, Feelisch M, Moncada S Persistent inhibition of cell respiration by nitric oxide: crucial role of S-nitrosylation of mitochondrial complex I and protective action of glutathione. Proc Nat Acad Sci U S A 1998;95:7631 -6.

29. Beltran B, Mathur A, Duchen MR, Erusalimsky JD, Moncada S. The effect of nitric oxide on cell respiration: a key to understanding its role in cell survival or death. Proc Natl Acad Sci U S A 2000;97:14602-7. 30. Sonveaux $P$, Dessy $C$, Brouet $A$, et al. Modulation of the tumor vasculature functionality by ionizing radiation accounts for tumor radiosensitization and promotes gene delivery. FASEB J 2002;16:1979-81. 
31. Sonveaux $P$, Dessy $C$, Martinive $P$, et al. Endothelin1 is a critical mediator of myogenic tone in tumor arterioles: implications for cancer treatment. Cancer Re 2004;64:3209-14

32. Dessy C, Moniotte S, Ghisdal P, Havaux X Noirhomme P, Balligand JL. Endothelial $\beta 3$-adrenoceptors mediate vasorelaxation of human coronary microarteries through nitric oxide and endothelium dependent hyperpolarization. Circulation 2004;110 948-54.

33. Ansiaux R, Baudelet C, Jordan BF, et al. Mechanism of reoxygenation after antiangiogenic therapy using SU5416 and its importance for guiding combined antitumor therapy. Cancer Res 2006:66:9698-704.

34. Mosmann T. Rapid colorimetric assay for cellular growth and survival: application to proliferation and cytotoxicity assays. J Immunol Methods 1983;65 $55-63$
35. Wouters BG, Brown JM. Cells at intermediate oxygen levels can be more important than the "hypoxic fraction" in determining tumor response to fractionated radiotherapy. Radiat Res 1997; 147:541 - 50.

36. Ilangovan $\mathrm{G}$, Li $\mathrm{H}$, Zweier JL, Kuppusamy P. In vivo measurement of tumor redox environment using EPR spectroscopy. Mol Cell Biochem 2002;234-235: 393-8.

37. Samouilov A, Kuppusamy P, Zweier JL. Evaluation of the magnitude and rate of nitric oxide production from nitrite in biological systems. Arch Biochem Biophys 1998;357:1 - 7

38. Stamler JS, Jia L, Eu JP, et al. Blood flow regulation by S-nitrosohemoglobin in the physiological oxygen gradient. Science 1997;276:2034-7.

39. Cosby K, Partovi KS, Crawford JH, et al. Nitrite reduction to nitric oxide by deoxyhemoglobin vasodilates the human circulation. Nat Med 2003;9:1498-505.
40. Huang Z, Shiva S, Kim-Shapiro DB, et al. Enzymatic function of hemoglobin as a nitrite reductase that produces NO under allosteric control. J Clin Invest 2005; 115:2099-107.

41. Doherty DH, Doyle MP, Curry SR, et al. Rate of reaction with nitric oxide determines the hypertensive effect of cell-free hemoglobin. Nat Biotechnol 1998; 16:672-6

42. Lala PK, Chakraborty C. Role of nitric oxide in carcinogenesis and tumour progression. Lancet Oncol 2001;2:149-56.

43. Pluta RM, Dejam A, Grimes G, Gladwin MT, Oldfield EH. Nitrite infusions to prevent delayed cerebral vasospasm in a primate model of subarachnoid hemorrhage. JAMA 2005;293:1477-84.

44. Holland MA, Kozlowski LM. Clinical features and management of cyanide poisoning. Clin Pharm 1986; $5: 737-41$ 